Jurnal Ilmiah Farmasi (Scientific Journal of Pharmacy) 17(2) Agustus-Desember 2021, 107-114

ISSN: 1693-8666

available at http://journal.uii.ac.id/index.php/JIF

\title{
Identification of waste: DOWNTIME in the outpatient prescription services at the pharmacy installation of Rumah Sakit Islam Siti Hajar Mataram
}

\section{Identifikasi waste: DOWNTIME pada pelayanan resep rawat jalan di instalasi farmasi Rumah Sakit Islam Siti Hajar Mataram}

\author{
Nur Atikah ${ }^{*}$, Sari Nanchi Parhatiwi², Ajeng Dian Pertiwi², Evi Fatmi Utami², Firman ${ }^{3}$ \\ ${ }^{1}$ Poltekkes Kemenkes Surakarta, Surakarta, Indonesia \\ 2 Politeknik Medica Farma Husada Mataram, Mataram, Indonesia \\ ${ }^{3}$ Divisi Manajemen RS PKMK FK-KMK UGM, Yogyakarta, Indonesia \\ *Corresponding author: ika.nuratikah01@gmail.com
}

\begin{abstract}
Background: The hospital pharmacy installation is a health service unit that is required to provide professional services and improve quality which is oriented towards achieving patient satisfaction. Waste identification in pharmaceutical services is important because it has an impact on stakeholder satisfaction.

Objective: Identifying waste using the DOWNTIME method for the outpatient prescription services at the pharmacy installation of Rumah Sakit Islam Siti Hajar Mataram.

Methods: The study used the cross-sectional design, with the population being all outpatients who were provided with pharmaceutical services during February - April 2019 as well as all staff. Data were tabulated and analyzed descriptively. Critical waste was obtained through questionnaires and the root causes of critical waste were obtained through in-depth interviews with 5-why methods.

Results: Waste waiting had the highest rate compared to other wastes, reaching $44 \%$ or 53 out of 121 respondents, followed by inventory (26\%), extra processing (19\%), transportation (14\%), defects (14\%), motion (13\%), over production (8\%), and non-utilized skills (7\%). Meanwhile, from the staff respondents, waiting was also the highest waste (18\%), followed by inventory (16\%), motion (13\%), over production (12\%), transportation (12\%), non-utilized skills (10\%), extra processing (10\%), and defects $(9 \%)$. The root cause of waste waiting was the frequent drug unavailability due to delays in payment of services from the cooperating party to the hospital as well as the narrow service areas.

Conclusion: Waste waiting became the critical waste with the highest percentage of dissatisfaction in the patient respondents (44\%) and staff respondents (18\%).

Keywords: Waste, DOWNTIME, outpatient prescription services, pharmacy installation of RSI Siti Hajar Mataram

\section{Intisari}

Latar belakang: Instalasi farmasi rumah sakit (IFRS) merupakan unit pelayanan kesehatan yang diharuskan untuk melayani secara profesional dan meningkatkan mutu yang berorientasi pada tercapainya kepuasan pasien. Identifikasi waste dalam pelayanan kefarmasian penting, karena berdampak kepada kepuasan stakeholder.

Tujuan: Melakukan identifikasi waste dengan metode DOWNTIME di IFRS Rawat Jalan RSI Siti Hajar Mataram. Metode: Desain penelitian adalah cross sectional, dengan populasi seluruh pasien rawat jalan yang diberikan pelayanan kefarmasian pada bulan Februari-April tahun 2019, dan seluruh staf IFRS. Data ditabulasi dan dianalisis secara deskriptif. Waste kritis diperoleh melalui penyebaran kuisioner dan akar penyebab waste kritis diperoleh melalui wawancara mendalam dengan metode 5 why.

Hasil: Waste waiting mendapat angka paling tinggi dibandingkan waste yang lainnya, dimana $44 \%$ atau 53 responden dari 121 responden. Kemudian disusul oleh inventory (26\%), extra preccesing (19\%), transportation (14\%), defect (14\%), motion (13\%), over production (8\%) dan non-utilized skill (7\%). Bagi responden staf IFRS, waiting juga menjadi waste tertinggi (18\%), diikuti oleh inventory (16\%), motion (13\%), over production (12\%),
\end{abstract}


108 | Atikah, dkk/Jurnal Ilmiah Farmasi (Scientific Journal of Pharmacy) 17(2) Agustus-Desember 2021, 107114

transportation (12\%), non-utilized skill (10\%), extra processing (10\%), dan defect (9\%). Akar penyebab waste waiting adalah sering terjadi kekosongan obat akibat keterlambatan pembayaran jasa pelayanan dari pihak kerjasama kepada rumah sakit serta area pelayanan yang sempit.

Kesimpulan: Waste waiting menjadi waste kritis dengan persentase ketidakpuasan tertinggi pada responden pasien (44\%) dan pada responden staf (18\%).

Kata kunci : Waste, DOWNTIME, pelayanan resep, pasien rawat jalan, IFRS RSI Siti Hajar Mataram

\section{Pendahuluan}

Rumah sakit adalah institusi pelayanan kesehatan yang berfungsi menyelenggarakan pelayanan kesehatan perorangan secara paripurna yang menyediakan pelayanan rawat inap, rawat jalan, dan gawat darurat (Kemenkes, 2018). Menurut Undang- Undang Republik Indonesia nomor 44 tahun 2009 tentang rumah sakit, selain mempunyai fungsi sosial, rumah sakit harus diselenggarakan berdasarkan nilai kemanusiaan, etika dan profesionalitas, manfaat, keadilan, persamaan hak dan anti untuk diskriminasi, pemerataan, perlindungan serta dapat berorientasi kepada keselamatan pasien (Anonim, 2009). Layanan kefarmasian selain menjadi tuntutan profesionalisme juga dapat dilihat sebagai faktor mengevaluasi kepuasan pasien (Yaqin, 2017). Mengidentifikasi waste manajemen dalam kegiatan pelayanan kefarmasian penting adanya karena hal tersebut berdampak kepada kepuasan stakeholder (Putri, 2017).

Waste atau pemborosan dapat diartikan segala aktivitas tidak bernilai tambah dalam proses, dimana aktivitas-aktivitas itu hanya menggunakan sumber daya namun tidak memberikan nilai tambah kepada pelanggan. Semua waste harus dihilangkan atau minimal dikurangi, tidak hanya demi meningkatkan keselamatan pasien dan pegawai namun juga demi meningkatkan kepuasan pasien dan menekan biaya rumah sakit (Sari, 2018). Waste yang umum ditemukan termasuk dalam pelayanan rumah sakit yaitu defect, over production, waiting, non-utilized skill, transportation, inventory, motion dan extra processing atau disingkat DOWNTIME (Firman et al., 2019).

Pada penelitian yang dilakukan di Instalasi Farmasi Rawat Jalan RSI PKU Muhammadiyah Pekajangan dengan metode DOWNTIME ditemukan waste kritis atau pemborosan yang paling sering ditemukan adalah motion dengan presentase 19\%. Hal tersebut disebabkan area farmasi yang tidak terlalu besar sehingga proses mencari perbekalan farmasi membutuhkan waktu lebih lama (Putri, 2017). Waste kritis inventory pun teridentifikasi di Instalasi Farmasi Rawat Jalan Rumah Sakit Anna Medika Bekasi. Hal tersebut disebabkan persediaan obat-obatan dan alat kesehatan yang menumpuk sehingga penataan barang menjadi sulit (Dima, 2015).

Penelitian identifikasi waste manajemen tidak pernah dilakukan sebelumnya di sarana pelayanan kesehatan di Mataram, khususnya instalasi farmasi RSI Siti Hajar Mataram. Tujuan penelitian ini adalah untuk identifikasi waste dengan metode DOWNTIME. Diharapkan hasil penelitian dan saran perbaikan dari penelitian ini dapat diterapkan sehingga membantu dalam 
109 | Atikah, dkk/Jurnal Ilmiah Farmasi (Scientific Journal of Pharmacy) 17(2) Agustus-Desember 2021, 107114

perbaikan manajemen instalasi farmasi dan meningkatkan kepuasan pasien terhadap pelayanan IFRS.

\section{Metode}

Penelitian ini merupakan penelitian deskriptif cross-sectional. Pengambilan data dilakukan di Instalasi Farmasi Rumah Sakit (IFRS) Islam Siti Hajar Mataram, dengan menggunakan survei kuisioner dan observasi partisipasif.

\subsection{Deskripsi subjek uji dan teknik pengumpulan sampel}

Populasi dari penelitian ini adalah pasien rawat jalan dan staf IFRS yang memenuhi kriteria inklusi dan eksklusi. Kriteria inklusi adalah pasien poli rawat jalan yang mendapatkan resep dokter dan menebusnya di IFRS RSI Siti Hajar Mataram pada bulan Februari-April tahun 2019, untuk staf Instalasi Farmasi Rawat Jalan RSI Siti Hajar Mataram dipilih yang telah bekerja minimal 1 tahun, sedangkan kriteria eksklusi penelitian ini adalah pasien dan staf yang tidak bersedia menjadi responden. Cara pengambilan sampel menggunakan teknik Non-Random Accidental Sampling.

Sampel dihitung menggunakan rumus besar sampel deskriptif kategorik (Dahlan, 2013) yaitu:

$$
\mathrm{n}=\frac{\mathbf{Z} \boldsymbol{\alpha}^{2} \mathbf{P Q}}{\mathbf{d}^{2}}
$$

Keterangan:

$\mathrm{n} \quad=$ Ukuran sampel

$\mathrm{Z} \alpha \quad=$ Nilai standar dari Alpha, diperoleh dari table Z kurva normal. Untuk nilai standar Alpha 5\% yaitu 1,96

$\mathrm{P} \quad$ = Proporsi dari kategori yang menjadi point of interest, nilai yang diperoleh dari kepustakaan, studi pendahuluan atau asumsi. Nilai proporsi pravalensi dari penelitian waste atau pemborosan sebelumnya 19\% (Putri, 2017)

$\mathrm{Q} \quad=$ Proporsi, $\mathrm{Q}=1-\mathrm{P}$

$\mathrm{d} \quad=$ Presisi penelitian, yaitu kesalahan prediksi proporsi yang masih dapat diterima, ditetapkan 7\%

Berdasarkan perhitungan sampel, diperoleh minimal 121 sampel responden pasien rawat jalan di IFRS Siti Hajar Mataram, sedangkan untuk staf IFRS diambil seluruh populasi yaitu sebanyak 12 orang untuk mendukung analisis identifikasi waste dari pasien.

\subsection{Deskripsi jalannya penelitian}

Penelitian didahului dengan observasi langsung proses pelayanan yang terjadi di IFRS RSI Siti Hajar Mataram mulai pasien datang sampai selesai mendapatkan pelayanan. Tahap selanjutnya yaitu pengisian informed consent oleh staf dan pasien sebagai pernyataan kesediaan mengikuti penelitian, kemudian dilakukan penyebaran kuisioner. Kuisioner untuk pasien berisi kategori waste beserta 
110 | Atikah, dkk/Jurnal Ilmiah Farmasi (Scientific Journal of Pharmacy) 17(2) Agustus-Desember 2021, 107 114

contoh aktivitas pelayanan dari staf IFRS yang mewakili gambaran waste yang terjadi, kemudian terdapat kolom pernyataan puas atau tidak puas dari bentuk aktivitas tersebut. Kuisioner untuk staf IFRS berisi kategori waste beserta contoh aktivitas pelayanan yang biasa dilakukan staf IFRS yang mewakili gambaran waste yang terjadi, kemudian terdapat kolom peringkat dari setiap kategori waste. Tahap akhir yaitu wawancara mendalam dengan staf IFRS RSI Siti Hajar Mataram. Dari hasil kuisioner diambil 3 waste yang mendapatkan persentase tertinggi dan dicari penyebab dari waste tersebut melalui wawancara. Wawancara menggunakan metode five why (5 Why), yaitu metode wawancara tidak terstruktur dan bebas dimana informasi diperoleh secara spontanitas mengenai pengembangan dan observasi yang diajukan kepada informan (Putri, 2017).

\subsection{Analisis Data}

Data yang diperoleh dari kuisioner pasien diolah dengan menghitung persentase responden yang puas dan tidak puas, sehingga diperoleh waste yang mendapat persentase tertinggi dan akan menjadi waste kritis. Hasil kuisioner staf akan diolah dengan metode Borda. Berdasarkan hasil wawancara yang dilakukan dengan responden Apoteker Penanggungjawab dapat diketahui penyebab waste kritis yang didapat dari hasil kuisioner dengan responden pasien dan staf IFRS RSI Siti Hajar Mataram.

\section{Hasil dan Pembahasan}

Berdasarkan hasil kuisioner dengan responden pasien diperoleh waste waiting mendapat angka ketidakpuasan pasien paling tinggi dibandingkan waste yang lainnya (gambar 1). Waste waiting yang sering terjadi pada pelayanan resep rawat jalan di IFRS RSI Siti Hajar adalah lamanya waktu tunggu pasien pada saat pelayanan resep dari mulai menyerahkan resep hingga pasien menerima obat. Waste waiting adalah proses menunggu prosedur atau aktivitas berikutnya, contoh dalam pelayanan rumah sakit adalah pasien menunggu pelayanan di poliklinik, menunggu penyerahan obat di instalasi farmasi (Firman et al., 2019). Selain itu, waste waiting (menunggu) juga dapat diartikan sebagai waktu dimana tidak ada aktivitas yang berlangsung contoh yang sering terjadi di lapangan seperti pasien menunggu antrian obat, proses pelayanan terlambat dimulai karena pegawai datang terlambat, menunggu proses administrasi yang berbelit, pegawai menunggu karena workload terlalu padat, dan lain sebagainya (Putri, 2017). Standar Pelayanan Minimal Rumah Sakit menurut Surat Keputusan Menteri Kesehatan Republik Indonesia Nomor 129/Menkes/SK/II/2008, terdapat 21 jenis pelayanan rumah sakit yang minimal wajib disediakan 
111 | Atikah, dkk/Jurnal Ilmiah Farmasi (Scientific Journal of Pharmacy) 17(2) Agustus-Desember 2021, 107114

oleh rumah sakit, salah satunya adalah pelayanan farmasi yang meliputi waktu tunggu pelayanan untuk obat jadi $\geq 30$ menit dan obat racikan $\geq 60$ menit (Kemenkes, 2008).

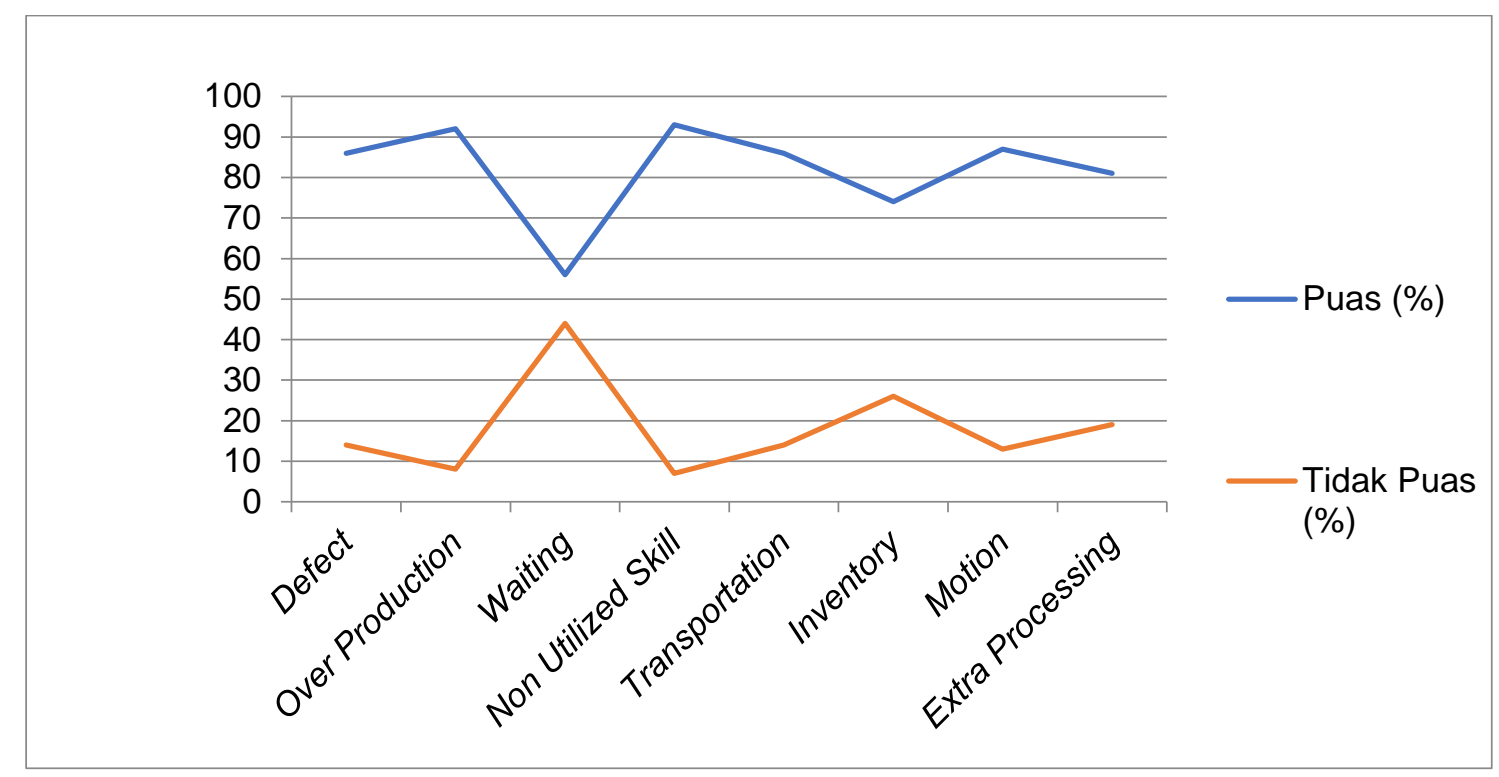

Gambar 1. Grafik distribusi data kepuasan responden (pasien)

Dari tabel 1, diketahui bahwa waiting kembali menjadi waste kritis atau jenis pemborosan yang paling sering terjadi pada pelayanan resep rawat jalan di IFRS RSI Siti Hajar Mataram menurut staf IFRS. Menurut staf, waktu yang diperlukan dari menerima resep hingga menyerahkan obat bisa lebih dari 60 menit untuk resep racikan. Hal tersebut terjadi karena resep sering masuk ke IFRS dalam waktu yang bersamaan dari berbagai poli rawat jalan, seperti poli jantung, poli paru, poli penyakit dalam, poli kejiwaan, poli syaraf dan lainnya, sehingga proses input resep ke dalam sistem komputer IFRS menjadi lama yang akibatnya proses penyiapan obat-obatan akan memakan waktu lebih lama lagi. Selain itu, terkadang stok obat habis, terutama untuk pasien kerjasama (BPJS Kesehatan, PT. Telkom, dll), padahal obat harus tetap disediakan, sehingga staf akan mencari dan membeli obat tersebut dari apotek luar untuk memenuhi kekosongan stok, akibatnya dibutuhkan waktu lebih lama dalam menyediakan obat. Efek kekosongan obat juga berdampak pada pasien umum, resep yang masuk ke IFRS tetap harus diinput ke dalam sistem komputer, ketika input inilah baru diketahui bahwa stok obat kosong, sehingga staf harus menuliskan copy resep untuk pasien membeli obat di apotek luar rumah sakit. 
112 | Atikah, dkk/Jurnal Ilmiah Farmasi (Scientific Journal of Pharmacy) 17(2) Agustus-Desember 2021, 107 114

Tabel 1. Distribusi data kuisioner dengan responden staf IFRS

\begin{tabular}{lcccccccccc}
\hline \multirow{1}{*}{ Waste } & \multicolumn{8}{c}{$\begin{array}{c}\text { Peringkat/ } \\
\text { Ranking }\end{array}$} & Skor & $\begin{array}{c}\text { Bobot } \\
\text { Total } \\
\text { (\%) }\end{array}$ \\
\cline { 2 - 7 } & $\mathbf{1}$ & $\mathbf{2}$ & $\mathbf{3}$ & $\mathbf{4}$ & $\mathbf{5}$ & $\mathbf{6}$ & $\mathbf{7}$ & $\mathbf{8}$ & & $9 \%$ \\
\hline Defect & 1 & 1 & 0 & 2 & 1 & 1 & 1 & 5 & 39 & $12 \%$ \\
\hline Over production & 1 & 1 & 3 & 1 & 0 & 1 & 5 & 0 & 51 & $18 \%$ \\
\hline Waiting & 6 & 2 & 0 & 0 & 2 & 2 & 0 & 0 & 76 & $10 \%$ \\
\hline Non utilized Skill & 0 & 0 & 2 & 2 & 3 & 2 & 2 & 1 & 45 & $16 \%$ \\
\hline Transportation & 0 & 1 & 2 & 4 & 1 & 1 & 1 & 2 & 50 & $13 \%$ \\
\hline Inventory & 3 & 3 & 2 & 2 & 0 & 1 & 0 & 1 & 71 & $10 \%$ \\
\hline Motion & 0 & 3 & 3 & 0 & 3 & 1 & 1 & 1 & 57 & $\mathbf{1 0 0 \%}$ \\
\hline Extra processing & 1 & 1 & 0 & 1 & 1 & 4 & 2 & 2 & 42 & \\
\hline \multicolumn{1}{c}{ Bobot } & $\mathbf{8}$ & $\mathbf{7}$ & $\mathbf{6}$ & $\mathbf{5}$ & $\mathbf{4}$ & $\mathbf{3}$ & $\mathbf{2}$ & $\mathbf{1}$ & $\mathbf{4 3 1}$ & \\
\hline \multicolumn{1}{c}{} & & & & & & & & & & \\
\hline
\end{tabular}

Penelitian ini selaras dengan hasil penelitian identifikasi waste di RSUD Wates, yang menunjukkan bahwa waste waiting merupakan waste kritis dengan persentase 24,4\% (Sari, 2018). Berbeda dalam hal penyebab waste waiting dengan penelitian ini, pada penelitian di RSUD Wates disebabkan oleh lamanya penggunaan server SIMRS, keterbatasan jumlah SDM dan dipengaruhi faktor tata ruang serta alur proses pelayanan. Penelitian yang dilakukan di RS PKU Muhammadiyah Bantul juga menunjukkan waste kritis yang terjadi adalah waste waiting, tapi penyebab hal tersebut karena SIM (Sistem Manajemen Informasi) Rumah Sakit mengalami error dan banyak petugas yang terbebani double job (Triyani, 2019). Penelitian tersebut juga menunjukkan waste kritis berupa overprocessing, yang disebabkan karena banyak aktivitas yang dilakukan berulang, seperti telaah resep yang dilakukan berulang dan penulisan e-tiket yang dilakukan dua kali. Penelitian yang dilakukan di RSUD Dr. Soeradji Tirtonegoro mengenai analisis waste kritis, juga menunjukkan bahwa waste kritis ada pada overprocessing (26\%), penyebabnya yaitu banyak proses pelayanan yang masih dilakukan secara manual, sehingga dianggap kurang efektif dan buang-buang waktu (Rochimah \& Mudayana, 2020). Perbedaan jenis dan penyebab waste kritis berbagai penelitian sebelumnya dengan penelitian ini disebabkan oleh adanya perbedaan pada kondisi sarana dan prasarana serta manajemen rumah sakit.

Berdasarkan wawancara yang dilakukan dengan metode 5 Why, maka dapat diketahui bahwa yang menjadi akar penyebab dari waste kritis adalah adanya keterlambatan pembayaran jasa pelayanan dari pihak kerjasama kepada RSI Siti Hajar Mataram, sehingga terjadi keterlambatan pembayaran obat-obatan yang sudah jatuh tempo. Hal tersebut mengakibatkan sering terjadi kekosongan obat. Selain itu, ruang IFRS yang terlalu sempit sehingga ruang gerak staf menuju tempat penyiapan resep sering terhambat. Apabila dilihat dari layout alur pelayanan IFRS, alur pelayanan sudah berjalan secara sistematis. Namun, tumpukan arsip serta stok obat hampir mengambil 
113 | Atikah, dkk/Jurnal Ilmiah Farmasi (Scientific Journal of Pharmacy) 17(2) Agustus-Desember 2021, 107 114

sebagian dari badan jalan menuju ke tempat penyiapan resep. Secara keseluruhan, area IFRS tidak terlalu besar sehingga tidak memungkinkan untuk disediakan ruang arsip dan tempat penyimpanan lemari obat agar stok obat dapat disusun dengan rapi.

Menurut Permenkes tahun 2016 tentang standar pelayanan kefarmasian di rumah sakit, pelayanan kefarmasian harus didukung oleh sumber daya manusia, sarana, dan peralatan agar dapat meningkatkan mutu pelayanan kefarmasian (Kemenkes, 2016). Beberapa fasilitas yang harus tersedia diantaranya tersedianya fasilitas penyimpanan barang farmasi yang menjamin semua barang farmasi tetap dalam kondisi yang baik serta fasilitas untuk penyimpanan arsip resep. Seringnya terjadi kekosongan stok obat serta sempitnya ruang gerak staf dalam proses menyiapkan resep pasien, akan menambah waktu tunggu pasien dalam menerima obatnya, sehingga waiting menjadi waste kritis terbesar yang tidak terhindarkan.

Berangkat dari akar masalah tersebut, ide perbaikan yang diusulkan adalah melakukan eliminasi waste kritis secara intensif, salah satu cara yang dapat dilakukan dengan menerapkan pendekatan lean management secara menyeluruh. Lean merupakan suatu upaya terus menerus untuk mengeliminasi waste dan meningkatkan nilai tambah atau value added produk baik dalam bentuk barang maupun jasa agar memberikan nilai kepada pelanggan (Firman et al., 2019). Salah satu tools dari pendekatan lean management yang ditawarkan untuk diterapkan pada IFRS RSI Siti Hajar Mataram adalah tool 5S (Sort, Set, Shine, Standardized, Sustain). Tool 5S dilaporkan sebagai salah satu metode yang sangat unggul dalam konsep lean karena dikenal sebagai metode yang sederhana dan mudah dimengerti. 5S merupakan metode untuk mengatur tempat kerja, mengurangi waktu serta gerakan yang tidak perlu bagi karyawan sehingga membuat masalah menjadi lebih mudah terlihat, menciptakan efisiensi dan terhindar dari pemborosan tempat kerja. Penerapan 5S pada dasarnya bertujuan untuk meningkatkan produktifitas dan aliran, meningkatkan kualitas pelayanan dan mengurangi biaya/ beban organisasi. Penelitian yang lain menunjukkan bahwa terdapat hubungan antara penerapan pendekatan 5S dengan pengurangan waktu tunggu pasien di instalasi rawat jalan Rumah Sakit Tanzania (Ishijima et al., 2016).

\section{Kesimpulan}

Waste kritis yang terjadi pada IFRS RSI Siti Hajar Mataram yaitu waiting dengan persentase $44 \%$ pada responden pasien dan $18 \%$ pada responden staf. 
114 | Atikah, dkk/Jurnal Ilmiah Farmasi (Scientific Journal of Pharmacy) 17(2) Agustus-Desember 2021, 107 114

\section{Ucapan terimakasih}

Terimakasih kepada Rumah Sakit Islam Siti Hajar Mataram atas kesempatan kerjasama yang diberikan sehingga penelitian ini dapat terlaksana.

\section{Daftar pustaka}

Anonim. (2009). Undang-Undang Republik Indonesia Nomor 44 Tahun 2009 tentang Rumah Sakit. Jakarta

Dahlan, M. S. (2013). Besar Sampel dan Cara Pengambilan Sampel (3 Ed.). Jakarta Salemba Medika.

Dima, Z. L. (2015). Penggunaan Konsep Lean untuk Meningkatkan Efisiensi Pelayanan Instalasi Farmasi Rawat Jalan di Rumah Sakit Anna Medika Bekasi. Jurnal Administrasi Rumah Sakit, 2(1), 29-42.

Firman, F., Utarini, A., Koentjoro, T., \& Widodo, K. H. (2019). Implementasi Lean Six Sigma untuk Menurunkan Lead Time Pasien Emergensi Maternal di Unit Emergensi Maternal RSUD Panembahan Senopati Bantul. (Doktoral). UGM, Yogyakarta.

Ishijima, H., Eliakimu, E., \& Mshana, J. M. (2016). The "5S" approach to improve a working environment can reduce waiting time: Findings from hospitals in Northern Tanzania. The TQM journal: the international review of organizational improvement, 28(4), 664-680.

Kemenkes. (2008). Keputusan Menteri Kesehatan Republik Indonesia Nomor 129/ Menkes/ SK/ II/ 2008 tentang Standar Pelayanan Minimal Rumah Sakit. Jakarta: Kementerian Kesehatan RI

Kemenkes. (2016). Keputusan Menteri Kesehatan Republik Indonesia Nomor 72 Tahun 2016 tentang Standar Pelayanan Farmasi Di Rumah Sakit. Jakarta: Kementrian Kesehatan RI

Kemenkes. (2018). Peraturan Menteri Kesehatan Nomor 4 Tahun 2018 tentang Kewajiban Rumah Sakit dan Kewajiban Pasien. Jakarta: Kementerian Kesehatan RI

Putri, L. R. (2017). Pendekatan Lean Hospital untuk Mengidentifikasi Waste Kritis di Instalasi Farmasi Rawat Jalan RSI PKU Muhammadiyah Pekajangan. (Master). Universitas Muhammadiyah Yogyakarta, Yogyakarta.

Rochimah, S. F., \& Mudayana, A. A. (2020). Waste Kritis Pada Instalasi Farmasi Rawat Jalan RSUP Dr. Soeradji Tirtonegoro : Lean Management Approach. Environmental Occupational Health and Safety Journal, 1(1), 81-100.

Sari, I. M. P. (2018). Pendekatan Lean Hospital untuk Mengidentifikasi Waste Kritis di Instalasi Farmasi Rawat Jalan Rumah Sakit Umum Daerah Wates. (Master). Universitas Muhammadiyah Yogyakarta, $\quad$ Yogyakarta. Retrieved from http://repository.umy.ac.id/handle/123456789/22296

Triyani, T. (2019). Analisis Waste (Pemborosan) pada Instalasi Farmasi Rawat Jalan Menggunakan Pendekatan Lean Management di RS PKU Muhammadiyah Bantul. (Bachelor). Universitas Ahmad Dahlan, Yogyakarta. Retrieved from http://eprints.uad.ac.id/id/eprint/14332

Yaqin, A. A. (2017). Evaluasi Kepuasan Pasien terhadap Pelayanan Kefarmasian di Instalasi Farmasi RSUD dr. R. Koesma Kabupaten Tuban. (Bachelor). Universitas Islam Negeri Maulana Malik Ibrahim, Malang. Retrieved from http://etheses.uin-malang.ac.id/id/eprint/9353 